\title{
Internet Addiction and Personality Traits among Youths of Rajkot District
}

\author{
Mohit M. Pandya 1
}

\begin{abstract}
ABATRACT
The purpose of present study was to find out correlation between the youths' Internet Addiction and Personality Traits. The said sample was 120 both males and females in equal numbers was selected through random sampling. Internet Addiction Inventory \&Personality Traits Inventory are tailor-made instruments, having sufficient reliability and validity. For the purpose of analysis, The Karl-Pearson ' $r$ ' technique was used. Present study reveals the result that there is no significant Negative correlation between the youths' Internet Addiction and Personality Traits. The authors suggest that there is a need to explore the rural and the urban youths' correlation in the line of above study.
\end{abstract}

Keywords: Internet Addiction and Personality Traits

\section{INTRODUCTION:}

Concept of internet addiction was first coined by Goldberg (1996) and by following DSM IV addiction criteria it was defined as "very strong desire or urge for using the internet" (Aboujaoude et al., 2006; Block, 2008; Korkeilaet al.2009).Internet is a technological tool which makes our life easier and has become an indispensable part of it while it's number of user population increases faster each day (Isman and Dabaj, 2004; Yapici, and Akbayin, 2012). Although internet plays an indirect role on these issues, internet addiction affects these issues directly (Akın, 2012; Young, 1998).

Young (2006) stated that internet is one of the things that influence our daily life because internet users more likely to spend their leisure time in the cyber community.Mythily, Qiu and Winslow (2008), Singapore is a multicultural city-state with a total resident population of just over 3.5 million people, the literacy rate of Singaporeans is $95.4 \%$. Result show that $84 \%$ of the resident with age 10 to 14 years age have started to use the internet, while the internet use for the age of 15 to 59 is $64 \%$. Besides that, $21 \%$ of Singaporean with 60 years and older age group has used the internet. Furthermore, 78\% of household in Singapore have at least one computer no matter is desktop or laptop at home and the $71 \%$ of household have access to the internet at home. The most important thing is $61 \%$ of the individuals are using the internet for leisure activities including playing/downloading games, listening to music or watching films.

${ }^{1}$ Ph.D. Research Scholar, Department of Psychology, Saurashtra University Rajkot- Gujarat 
Feel the necessity for using the internet in an increased proportion in order to get the satisfaction they desire (Lee and Shin, 2004); fail in their attempts to control, reduce or give up their internet usage (Widyanto and Griffiths, 2007). Furthermore social sharing sites like Facebook, Twitter, online games and online gambling causes an increase in the number of internet addiction cases and it is stated that internet addiction will become a serious problem in the near future (Andreassen et al., 2012; Herrera et al., 2010; Teke, 2011).

However, there has been the different point of views on the dimensions and definitions of the Big Five (Goldberg, 1993). A well-accepted personality dimensions include Emotional Stability, Extraversion, and Openness to Experience, Agreeableness, and Conscientiousness (Costa \& McCrae, 1995; Goldberg, 1993; Judge et al., 2002; McCrae \& Costa, 1989; Saucier, 1994).According to Goldberg (1993), Emotional Stability (ES) refers to those who are selfreliant, stable, and adaptable to new situations. This concept sometimes is called Neuroticism (Emotional Instability). Extraversion(E) is defined as those who are sociable, gregarious, assertive, and cheerful. Openness to Experience (O) refers to those who are curious, unconventional, and imaginative. Agreeableness (A) refers to those who have the tendency to be cooperative, generous, altruistic, and warm. Conscientiousness (C) is defined as those who are dependable, organized, persistent, and goal-oriented.

In short, thoughts, feelings, and behaviors that make a person different from another one are called "personality". In this context, there are many research studies investigating personal characteristics that teachers should have, which illustrates the growing importance of personality traits. However, today, it is impossible to say that there is a consensus on the characteristics of an effective teacher (Cubukcu, zenbas, Cetinbas, Sat \& Seker, 2012). Research studies examining personality are generally based on big five personality theory. According to big five personality theory there are five dimensions of personality which are (1) neuroticism, (2) extraversion, (3) openness, (4) agreeableness, (5) conscientiousness (Bacanl, İlhan, \& Aslan, 2009:262). In this research the big five personality theory is used as a framework in order to investigate the participants- personality.

METHOD: Study method is presented below.

\section{OBJECTIVES}

To check correlation between Internet Addiction and Personality Traits of Rajkot District youths.

\section{HYPOTHESIS}

There is no correlation between Internet Addiction and Personality Traits of Rajkot district youths. 


\section{Internet Addiction and Personality Traits among Youths of Rajkot District}

\section{SAMPLE}

The respondents of the present study 120 young people randomly selected from various Areas in Rajkot district. In present research the total sample consisted of 60 male and 60 female Rajkot district were chosen.

\section{TOOLS}

\section{Internet Addiction Test (IAT)}

The IAT was develop by Dr. Kimberly Young, 1998 and it consist of 20 questions was adopted to evaluate the respondents' level of internet addiction. Each item is scored using a five-point likert scale, a graded response can be selected ( $1=$ "rare" to $5=$ "always"). It covers the degree to which internet use affect daily routine, social life, productivity, sleeping pattern, and feeling. The minimum score is 20 while the maximum is 100 and the higher the score the greater the level of internet addiction. Three types of Internet-user groups were identified in accordance with the original scheme of Young and the scores ranging from 20 to 49 indicate minimal users while scores from 50 to 79 indicate moderate users and the scores from 80 to 100 indicate excessive users. The instrument has exhibited good psychometric properties in previous researches. The reliability for this questionnaire is 0.899 in Cronbach's Alpha (Sally, 2006).

\section{Personality Traits Test}

The Big Five personality traits were operationalized as the pat- terns of people's behaviors. The International Personality Item Pool (IPIP) (Goldberg, 1999) was used to measure participant's behaviors. The scale reflects the five-factor model traits: Emotional Stability (Cronbach $\alpha=.71$ ); Extroversion (Cronbach $\alpha=.71$ ); Openness to Experience (Cronbach $\alpha=.70$ ); Agreeableness (Cronbach $\alpha=.66$ ); and Conscientiousness (Cronbach $\alpha=.70$ ). Participants were asked to rate how accurately each statement described their behaviors. The scale contains 50 items with a 5 point scale ranging from Very Inaccurate (1) to Very Accurate (5). For example, the items are: "carry out my plans", "respect others", "do not like art", "make friend easily".

\section{PROCEDURE:}

In this research two test were administrated individually as well as on young people, which collecting data for the study before attempting the questionnaire the subjects were requested to read the instruction carefully and follow them in true spirits. While the data collection was completed then 'r' was used to check correlations. 


\section{RESULTS AND DISCUSSION}

\section{Table-1}

Correlation calculation between Internet Addiction and Personality Traits of Rajkot district youths.

\begin{tabular}{|c|c|c|c|c|c|}
\hline Sr. no. & Variables & $\mathrm{N}$ & $\mathrm{df}$ & $\mathrm{r}$ & $\begin{array}{c}\text { Sig. } \\
\text { Levels }\end{array}$ \\
\hline 1. & $\begin{array}{c}\text { Internet } \\
\text { Addiction }\end{array}$ & 120 & 118 & & \multirow{2}{*}{ N.S. } \\
\hline 2. & $\begin{array}{c}\text { Personality } \\
\text { Traits }\end{array}$ & 120 & 118 & & \\
\hline
\end{tabular}

We have seen the table no. 1 the correlation between Internet Addiction and Personality Traits that ' $r$ ' value $=-0.14$, so we can say that there was no significant correlation between the respondents Internet Addiction and Personality Traits. Here, the Negative $r$ value $=-0.14$, which was no significant at 0.05 levels.Hence, Hypothesis is therefore to be accepted andit concluded that there was no significance correlation between respondents Internet Addiction and their Personality Traits. It means that as Internet Addiction increases the Personality Traits is increases.

\section{CONCLUSION}

The study presented in Rajkot district youths'Internet Addiction and Personality Traits of which are not connected to each other in check. Variable Negative correlation was seen between the two. Thus, Youths'Internet Addiction and Personality Traitsis no correlated with There is Negative Correlation between each other.

\section{REFERENCES}

1.Goldberg L. R. (1992) "The development of Markers for the Big-Five Factor structure." Psychological Assessment. 26-42 
2.Goldberg, L. R. (1993). The Structure of Phenotypic Personality Traits. American Psychologist, 48, 26-34.

3. John, O. P., \& Srivastava, S. (1999). The Big-Five trait taxonomy: History, measurement, and theoretical perspectives. In L. A. Pervin \& O. P. John (Eds.), Handbook of personality: Theory and research (Vol. 2, pp. 102-138). New York: Guilford Press.

4. Jose M. Augusto Landa, Manuel Pulido Martos (2010) Emotionalintelligenceand personality traitsaspredictorsofpsychological well-being in Spanish undergraduates. Social behavior and personality, 38(6), 783-794@ Society for Personality Research (Inc.) DOI 10.2224/sbp.2010.38.6.783

5. Ramazan Hasanzadeh, Atefeh Beydokhti and et.al. (2012).The Prevalence of Internet Addiction among University Students: A General or Specific Problem? J. Basic. Appl. Sci. Res., 2(5)5264-5271, ISSN 2090-4304 Journal of Basic and Applied Scientific Research

7. Young K. S. and Rogers R. C. (1998). The relationship between depression and Internet addiction. CyberPsychology and Behavior, 1, 25-28.

8. Young, K.S. (1998) Caught in the Net: How to Recognize Internet addiction and A Winning Strategy for Recovery. New York, NY: John Wiley and Sons, Inc.

9. Young, K.Y.S. (2007). Cognitive Behavior Therapy with internet Addicts: Treatment Outcomes and implications, Cyberpsychology \& Behavior Volume 10, Number 5, 671-679. 